\title{
Hydrodefluorination of $N$-acetylheptafluoro-2-naphthylamine by zinc in aqueous ammonia: synthetic outcomes and mechanistic considerations
}

\author{
Alexey V. Reshetov, Galina A. Selivanova, Larisa V. Politanskaya, Irina V. Beregovaya, \\ Lyudmila N. Shchegoleva, Nadezhda V. Vasil'eva, Irina Yu. Bagryanskaya, \\ and Vitalij D. Shteingarts* \\ N.N. Vorozhtsov Institute of Organic Chemistry, Siberian Division of Russian Academy of \\ Sciences, 9 Ac. Lavrentjev Avenue, Novosibirsk, 630090, Russia \\ E-mail: shtein@nioch.nsc.ru
}

\begin{abstract}
Dedicated to Professor Usein M Dzhemilev on the occasion of his $65^{\text {th }}$ birthday
\end{abstract}
\begin{abstract}
Reduction of the $\mathrm{N}$-acetyl derivatives of heptafluoro-2-naphthylamine and its less fluorinated analogues by zinc in aqueous $\mathrm{NH}_{3}$ has been investigated as a possible general and concise route to partially fluorinated $N$-(2-naphthyl)acetamides and, accordingly, 2-naphthylamines inaccessible by other ways.

Quantum chemical calculations and CV measurement results have been used to discuss and justify the suggested reaction mechanism including two competing routes: fragmentation of a substrate radical anion and its complex with a zinc cation.
\end{abstract}

Keywords: $N$-(2-polyfluoronaphthyl)acetamides, polyfluoro-2-naphthylamines, zinc, aqueous ammonia, polyfluoroarene radical anions, quantum chemical calculations, cyclic voltammetry measurements, $\mathrm{X}$-ray analysis

\section{Introduction}

Fluorine containing aminonaphthalenes are of practical interest. Thus, application have found either some biologically active monofluoronaphthylamines, ${ }^{1}$ prepared by fluorine and amino group introduction in an aromatic nucleus, or perfluoro- $\beta$-naphthylamines and perfluoro- $\beta$ naphthylenediamines accessible via aminodefluorination of octafluoronaphthalene. ${ }^{2-5}$ The latter compounds can be used as building blocks for polyimides meant for manufacturing optical wave conductors. $^{6,7}$ Unlike this, aminonaphthalenes with partially fluorinated skeleton were until recently almost inaccessible for extensive study and application. 
At the same time, reductive defluorination of $\mathrm{N}$-acetyl derivatives of the polyfluoroanilines, readily accessible by ammonolysis of base polyfluoroarenes, with use of the simplest reductive system - zinc in aqueous ammonia - was developed as an unprecedentedly concise approach to previously difficultly accessible polyfluoroanilines containing 1-3 hydrogen atoms in a benzene ring, in particular in a position ortho to the amino group. ${ }^{8,9}$ Thanks to this, the area of quinolines and their functional derivatives polyfluorinated on a benzene ring has been opened for intensive elaboration. $^{9-13}$ We believed this methodology is possible to apply to $\mathrm{N}$-acetyl derivatives of perfluoronaphthylamines for preparing their less fluorinated analogues unsubstituted ortho to an amino group as potential building blocks for polyfluoronaphthoazaheterocycles, some of which also can be highly biologically active (for example, by analogy with mono- and difluorobenzoquinolines ${ }^{14}$ ).

Thereupon the purpose of this paper is to investigate reduction of the $\mathrm{N}$-acetyl derivative of heptafluoro-2-naphthylamine, the latter being easily prepared by ammonolysis of octafluoronaphthalene, ${ }^{5}$ and its less fluorinated analogues by zinc in aqueous $\mathrm{NH}_{3}$ as a possible general and concise route to partially fluorinated $N$-(2-naphthyl)acetamides and, accordingly, 2naphthylamines inaccessible by other ways.

\section{Results and Discussion}

\section{Reduction of polyfluorinated $N$-(2-naphthyl) acetamides by zinc in aqueous ammonia}

Reactions were carried out by analogy with the technique ${ }^{9}$ at ambient temperature, reagent ratios, durations and results of experiments are presented in Table 1 . In some cases the $\mathrm{ZnCl}_{2}$ and ethanol additives were used since electrolytes and organic cosolvents (to increase a substrate solubility) were shown to accelerate defluorination of polyfluoroarenes. ${ }^{8,9,15,16}$ Product distributions and structures of the first prepared individual compounds were determined by NMR spectra (discussed in special section, see below), and GC-MS.

Upon action of zinc on $N$-(heptafluoro-2-naphthyl)acetamide 1 in aqueous (34\%) ammonia within $24 \mathrm{~h} N$-(1,3,4,5,7,8-hexafluoro-2-naphthyl)acetamide $\mathbf{2}$ was formed as a main product alongside with $N$-(1,4,5,7,8-pentafluoro-2-naphthyl)acetamide $\mathbf{3}$ and $N$-(1,4,5,6,8-pentafluoro-2naphthyl)acetamide $\mathbf{4}$ - products of double hydrodefluorination of $\mathbf{1}$, the starting compound being incompletely consumed (Scheme 1; Table 1, entry 1).

In accordance with literature data, ${ }^{9}$ the additive of $\mathrm{ZnCl}_{2}$ (Table 1, entry 2) somewhat increased the conversion degree of amide 1 and the content of the main product $\mathbf{2}$ (up to $\sim 50 \%$ ). Amide 3 is apparently formed from $\mathbf{2}$, and compound $\mathbf{4}$ - as a result of reduction of $N-(1,3,4,5,6,8$ hexafluoro-2-naphthyl)acetamide. The latter is also derived through monodefluorination of amide 1 but does not accumulate in the reaction mixture, apparently, due to faster consumption compared with $\mathbf{2}$, the reasons for which being currently unclear and calling for a special work to be revealed. 


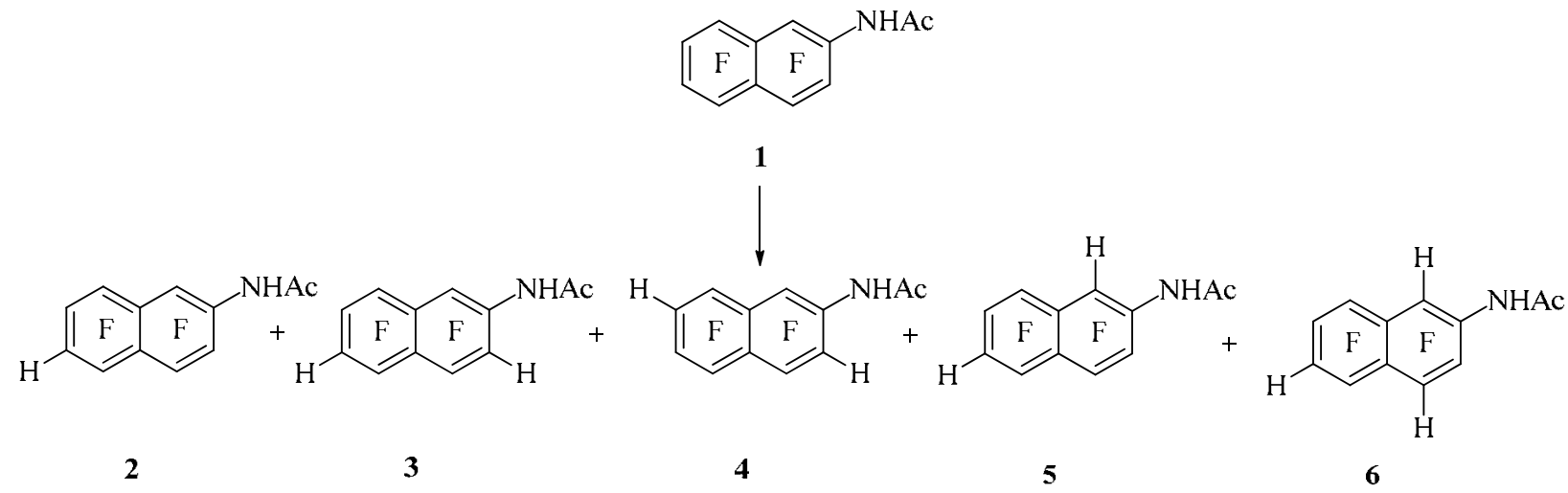

Scheme 1. Hydrodefluorination of acetamide 1.

Striving to obtain only a monohydrodefluorination product, reduction of $\mathbf{1}$ was carried out in two versions: by triple short-term $(6 \mathrm{~h})$ carrying out the reaction to avoid a significant transformation of the target product promoted by the zinc ions accumulating in a reaction course, and also in diluted (15\%) aqueous ammonia in the presence of ethanol (5.5:1 by volume) and $\mathrm{ZnCl}_{2}$ (Table 1, entries 3 and 4). As a result, in both cases amide 2 (NMR ${ }^{19} \mathrm{~F}$ ) appeared as a main product ( $70-80 \%, 50 \%$ isolated yield, entry 4$)$.

To check the possibility to prepare individual 3 and $\mathbf{4}$, the longer (till $70 \mathrm{~h}$ ) interaction duration in $25-30 \%$ aqueous ammonia with the $\mathrm{ZnCl}_{2}$ additive, particularly in combination with ethanol (Table 1, entries 5 and 6), amides 3 and 4 were found to form in a (5-7):1 ratio with the $60-65 \%$ total content and small admixture of two more compounds (NMR ${ }^{19} \mathrm{~F}$ data). This agreed with the GC-MS data, testifying the mixture formed (entry 5) to consist mainly of three double hydrodefluorination products $(\mathrm{M} \mathrm{275}$; the 52, 18, and 12\% contents) and the product of three fluorines removal from 1 (M 257, 10\%). On the basis of these data and NMR characteristics presented in Table 2 (the discussion see below), one might believe the minor products to be, besides 4, $N$-(3,4,5,7,8-pentafluoro-2-naphthyl)acetamide $\mathbf{5}$ and $N$-(3,5,7,8-tetrafluoro-2naphthyl)acetamide 6. The latter was identified by NMR with the authentic sample, the synthesis of which is presented below. Amides $\mathbf{5}$ and $\mathbf{6}$ are apparently formed from 2, however the sequence of fluorine atoms removal in the course of its conversion to 6 is not clear.

The individual 3 failed to be isolated from the product mixtures formed in these experiments as well as upon reduction of $\mathbf{2}$ in the systems $\mathrm{Zn}-\mathrm{ZnCl}_{2}$-aq. $\mathrm{NH}_{3}$ (34\%) with the ethanol additive (Table 1, entry 7). The purpose was achieved by reducing amide $\mathbf{2}$ in a mixture of aqueous (34\%) ammonia with an ammonia solution in ethanol and $\mathrm{ZnCl}_{2}$ (Table 1, entry 8) due to the complete conversion of $\mathbf{2}$ into $\mathbf{3}$ and its hydrolysis product - 1,4,5,7,8-pentafluoro-2naphthylamine 7 (61\% and $17 \%$ in a product mixture, respectively). The latter was obtained in a $47 \%$ isolated yield by heating amide 3 with the concentrated hydrochloric acid in ethanol and converted quantitatively to amide 3 by action of acetic anhydride in benzene by analogy to the synthesis of $1 .^{9}$ Amide $\mathbf{4}$ formed alongside with $\mathbf{3}$ was identified by NMR with the authentic sample, the synthesis of which will be described separately. 
Table 1. Reduction of compounds $\mathbf{1}$ and $\mathbf{2}$, conditions ${ }^{\mathrm{a}}$ and results

\begin{tabular}{|c|c|c|c|c|c|c|c|c|c|c|c|}
\hline \multirow[t]{2}{*}{ Entry } & \multirow{2}{*}{$\begin{array}{c}\text { Sub- } \\
\text { strate } \\
(\mathrm{mmol})\end{array}$} & \multirow{2}{*}{$\begin{array}{c}\text { Reducing } \\
\text { agent } \\
\text { (mmol) }\end{array}$} & \multirow{2}{*}{$\begin{array}{c}\text { Additives } \\
\text { (mg or } \mathrm{mL} \text { ) }\end{array}$} & \multirow{2}{*}{$\begin{array}{c}\text { Time } \\
\mathrm{h}\end{array}$} & \multicolumn{7}{|c|}{ Products, mol. \% ${ }^{\mathrm{b}}$} \\
\hline & & & & & 1 & 2 & 3 & 4 & 5 & 6 & 7 \\
\hline 1 & $\mathbf{1}(0.64)$ & $\mathrm{Zn}(6.5)$ & - & 24 & 42 & 38 & 10 & 8 & - & - & - \\
\hline 2 & $\mathbf{1}(0.64)$ & $\operatorname{Zn}(6.5)$ & $\mathrm{ZnCl}_{2}(884)$ & 24 & 24 & 52 & 11 & 9 & - & - & - \\
\hline 3 & $\mathbf{1}(1.66)$ & $\mathrm{Zn}(16.0)$ & - & $3 \times 6$ & 2 & 72 & 10 & 7 & - & - & - \\
\hline 4 & $\mathbf{1}(7.00)$ & $\mathrm{Zn}(192.0)^{\mathrm{c}}$ & $\begin{array}{c}\mathrm{ZnCl}_{2}(31 \mathrm{~g}) \\
\text { ethanol }(260)\end{array}$ & 48 & - & 80 & 8 & 4 & - & - & - \\
\hline 5 & $\mathbf{1}(0.90)$ & $\mathrm{Zn},(13.4)^{\mathrm{d}}$ & $\mathrm{ZnCl}_{2}(2760)$ & 70 & - & - & 53 & 10 & 15 & 13 & - \\
\hline 6 & $\mathbf{1}(0.50)$ & $\operatorname{Zn}(7.5)$ & $\begin{array}{c}\mathrm{ZnCl}_{2}(1537), \\
\text { ethanol (4.5) }\end{array}$ & 70 & - & 5 & 56 & 8 & 11 & 7 & - \\
\hline 7 & $2(0.34)$ & $\mathrm{Zn}(5.1)$ & $\begin{array}{c}\mathrm{ZnCl}_{2}(1047) \\
\text { ethanol (3) }\end{array}$ & 73 & - & 24 & 52 & - & 13 & 9 & - \\
\hline 8 & $2(0.5)$ & $\mathrm{Zn}(10.0)$ & $\begin{array}{c}\mathrm{ZnCl}_{2}(1360) \\
\text { ethanol (30) }\end{array}$ & 74 & - & - & 61 & - & 3 & 11 & 17 \\
\hline 9 & $2(0.47)$ & $\mathrm{Zn} / \mathrm{Cu}(4.1 \mathrm{~g})^{\mathrm{e}}$ & ethanol (2) & 190 & - & - & 18 & - & 3 & 13 & 50 \\
\hline 10 & $2(1.41)$ & $\mathrm{Zn} / \mathrm{Cu}(6.5 \mathrm{~g})^{\mathrm{f}}$ & - & 64 & - & - & 11 & - & - & 56 & - \\
\hline 11 & $1(0.50)$ & $\mathrm{Zn}(5.0)^{\mathrm{g}}$ & $\begin{array}{c}\mathrm{NH}_{4} \mathrm{SCN} \\
(380)\end{array}$ & 96 & - & 84 & - & - & - & - & - \\
\hline 12 & $2(0.14)$ & $\operatorname{Zn}(1.5)^{\mathrm{h}}$ & $\begin{array}{c}\mathrm{NH}_{4} \mathrm{SCN} \\
(114)\end{array}$ & 96 & - & 100 & - & - & - & - & - \\
\hline
\end{tabular}

a $30-34 \%$ aqueous ammonia, $5-8 \mathrm{~mL}$ on $1 \mathrm{mmol}$ of the reducing agent (if other is not specified).

${ }^{b}$ According to ${ }^{19} \mathrm{~F}$ NMR spectra. In cases when the total content is less than $100 \%$, there are not identified components. ${ }^{\mathrm{c}} 1440 \mathrm{~mL}$ of $14 \%$ aqueous ammonia. ${ }^{\mathrm{d}} 90 \mathrm{~mL}$ of $25 \%$ aqueous ammonia. ${ }^{\mathrm{e}} 70 \mathrm{~mL}$ of aqueous ammonia. ${ }^{\mathrm{f}} 200 \mathrm{~mL}$ of aqueous ammonia. ${ }^{\mathrm{g}} 50 \mathrm{~mL}$ of aqueous ammonia. ${ }^{\mathrm{h}} 25$ $\mathrm{mL}$ of aqueous ammonia.

The result similar to entry 8 (Table 1) was achieved after prolonged reduction of 2 by $\mathrm{Zn}-\mathrm{Cu}$ couple in concentrated aqueous ammonia with a small additive of ethanol, amine 7 being the main product in this case due to hydrolysis of $\mathbf{3}$ (Table 1, entry 9). The use of $\mathrm{Zn}-\mathrm{Cu}$ couple as a reducer allowed to propel the amide $\mathbf{2}$ hydrodefluorination until removal of two fluorine atoms to yield basically amide 6 ( $56 \%$ of a product mixture, Table 1, entry 10$)$ isolated by crystallization from ethanol in a 33\% yield. Its structure was confirmed by X-ray analysis. Reduction of $\mathbf{1}$ by $\mathrm{Zn}-\mathrm{Cu}$ couple in aqueous ammonia (34\%) led to complex mixtures of the products corresponding a removal of 3-5 fluorine atoms, including 6 (30-35\%). Amides 2 and 6 were smoothly hydrolyzed 
to 1,3,4,5,7,8-hexafluoro-2-naphthylamine 8 and 3,5,7,8-tetrafluoro-2-naphthylamine $\mathbf{9}$, respectively, in high yields (97-98\%).

The above regioselectivity data suggest that in going from $\mathbf{1}$ to $\mathbf{2}$ the main reaction channel is changed. Defluorination of $\mathbf{1}$ at the position 6, which is remote from the acetamido group, implies that the specific ortho-selectivity, revealed earlier for pentafluoroacetanilide $\mathbf{1 0}$ as catalysed by zinc cations, ${ }^{9}$ does not occur in this case. Unlike this, ortho-defluorination of 2 suggests this effect to operate. It was obvious that to check a reality of zinc cations implication to this difference, the reduction of these amides should be carried out in the presence of some additives blocking a participation of zinc cations in the process. Pursuing this, we studied an influence of some salts on a course of reduction of amide $\mathbf{1 0}$ (as a model substrate), $\mathbf{1}$ and $\mathbf{2}$ by zinc in aqueous ammonia.

\section{Influence of salt additives on a course of reduction of polyfluoroarylacetamides by zinc in aqueous ammonia}

Reduction of amide $\mathbf{1 0}$ (Scheme 2) was carried out in concentrated aqueous ammonia $(\mathrm{d}=0.87-0.89$, $7 \mathrm{~mL}$ per $1 \mathrm{mmol}$ of $\mathbf{1 0}$ ) for $25 \mathrm{~h}$ with the reagent molar proportion 10:Zn:additive $(\mathrm{A})=1: 10: 3$. The product distributions are shown in Table 2.

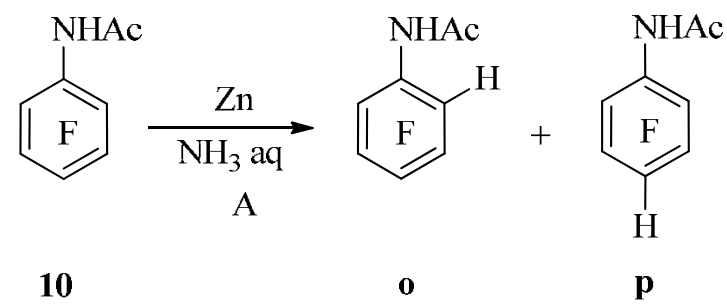

Scheme 2. Hydrodefluorination of pentafluoroacetanilide.

These data show the salt additives to more or less redistribute an ortho/para $(o / p)$ product ratio in favour of the latter, probable depending on their capability to counteract the complexation of amide 1 with a zinc cation (a special study is needed to reveal the reasons of certain salt effects), ammonium thiocyanate being most efficient. With use of this salt as an additive hydrodefluorination of $\mathbf{1}$ yielded only amide $\mathbf{2}$, whereas further defluorination was completely suppressed (Table 1, entry 11). Processing of 2 in the same conditions gave no any products, amide 2 remaining intact (Table 1, entry 12). In our opinion, this result convincingly testifies to a reality of the above change of a reaction channel in going from $\mathbf{1}$, which defluorination does not involve a specific participation of zinc cations, to 2 . The latter is not capable to be reduced in the same conditions, apparently, by virtue of its smaller electron-accepting ability compared with $\mathbf{1}$. This may well be caused by the lack of fluorine atom in position 6 , since the consecutive hydrodefluorination of polyfluorobenzenes in similar conditions is known to stop after the set of five or four neighboring fluorine atoms is destroyed. . $^{8,9,15,16}$ 
Table 2. Influence of salt additives on a product ratio of the amide $\mathbf{1 0}$ reduction

\begin{tabular}{ccc}
\hline $\mathrm{A}$ & $\begin{array}{c}\text { Substrate } \\
\text { conversion, } \%\end{array}$ & $o / p$ \\
\hline- & 71 & 3.4 \\
$\mathrm{ZnCl}_{2}$ & 75 & 4.8 \\
$\mathrm{Na}_{2} \mathrm{SO}_{4}$ & 70 & 4.7 \\
$\mathrm{KCl}$ & 78 & 2.7 \\
$\mathrm{KBr}$ & 69 & 2.9 \\
$\mathrm{KI}$ & 63 & 2.8 \\
$\mathrm{~K}_{2} \mathrm{SO}_{3}$ & 64 & 1.2 \\
$\mathrm{KSCN}_{\mathrm{NH}}$ & 70 & 1.4 \\
$\mathrm{NH}_{4} \mathrm{~F}$ & 86 & 0.4 \\
$\mathrm{NH}_{4} \mathrm{Cl}$ & 58 & 0.6 \\
$\left(\mathrm{NH}_{4}\right)_{2} \mathrm{SO}$ & 35 & 0.3 \\
$\mathrm{KCNO}_{4}$ & 63 & 0.2 \\
$\mathrm{NH}_{4} \mathrm{SCN}$ & 77 & 0.1 \\
\hline
\end{tabular}

NMR characteristics of polyfluorinated $N$-( $\beta$-naphthyl)acetamides (Table 3)

In a ${ }^{19} \mathrm{~F}$ NMR spectrum of amide 2 there are two pairs of signals having characteristic doublet splittings with $J(\mathrm{FF})_{\text {peri }}=63-65 \mathrm{~Hz}$, that testifies the presence of fluorine atoms at all four naphthalene $\alpha$-positions ( $\mathrm{cf}^{17,18}$ ). $\mathrm{F}^{1}, \mathrm{~F}^{3}, \mathrm{~F}^{4}$ and $\mathrm{F}^{8}$ have about the same chemical shift values $(\delta)$ as in a spectrum of amide 1. Unlike this, the signal at $\delta 45.5 \mathrm{ppm}$ (hereinafter relatively $\mathrm{C}_{6} \mathrm{~F}_{6}$ as an internal standard, $\delta_{\mathrm{F}}=0$ ) assigned to $\mathrm{F}^{5}$ is low-field shifted by $31.5 \mathrm{ppm}$ from that of $\mathbf{1}$ as a consequence of the fluorine replacement by hydrogen in a near-by ortho-position. ${ }^{16}$ For the similar reason the signal which is low-field shifted by $21.5 \mathrm{ppm}$ from its counterpart in $\mathbf{1}$ belongs to $\mathrm{F}^{7}$. In a ${ }^{1} \mathrm{H}$ NMR spectrum there are signals characteristic for an acetamide group (the signal at $\delta 9.2 \mathrm{ppm}$ belongs to $\mathrm{NH}$, and that at $\delta 2.2 \mathrm{ppm}$ - to methyl hydrogens), and also the signal at $\delta$ $7.6 \mathrm{ppm}$ assigned to $\mathrm{H}^{6}$ and having two doublet splittings with $J(\mathrm{HF})_{\text {ortho }}=12 \mathrm{~Hz}$ and one doublet splitting with $J(\mathrm{HF})_{\text {meta }}=6 \mathrm{~Hz}$ owing to coupling with $\mathrm{F}^{5}, \mathrm{~F}^{7}$ and $\mathrm{F}^{8}$, respectively.

Signals in spectra of amides $\mathbf{3}$ and $\mathbf{4}$ are referred basing on similar reasons. The particular feature of the ${ }^{19} \mathrm{~F}$ NMR spectra is that the $\mathrm{F}^{1}$ signals, besides splittings with $J(\mathrm{FF})_{\text {peri }}=63 \mathrm{~Hz}$ and $69 \mathrm{~Hz}$, respectively, have one more doublet splitting with $J(\mathrm{FF})=18 \mathrm{~Hz}$ which is typical for the interaction of $\alpha$-F atoms located para to each other in a naphthalene core. ${ }^{17,18}$ In a ${ }^{19} \mathrm{~F}$ NMR spectrum of $\mathbf{3}$, the $\mathrm{F}^{4}$ and $\mathrm{F}^{5}$ resonances are observed in a low field whereas in the case of $\mathbf{4}$ the signals of $\mathrm{F}^{4}$ and $\mathrm{F}^{8}$ are low-field located (Table 3). A ${ }^{19} \mathrm{~F}$ NMR spectrum of amide 6 contains 4 signals, no one of which having the peri-interaction splitting thus indicating an absence of pairs of fluorine atoms in adjacent $\alpha$-positions of the naphthalene core. 
Table 3. ${ }^{19} \mathrm{~F}$ and ${ }^{1} \mathrm{H}$ NMR characteristics of compounds 2-9 in $\mathrm{CDCl}_{3}$

\begin{tabular}{|c|c|c|c|c|c|c|c|c|}
\hline \multirow[t]{2}{*}{$\begin{array}{l}\text { Comp } \\
\text { ound }\end{array}$} & \multicolumn{8}{|c|}{$\begin{array}{l}\text { Position of the substituent }{ }^{1} \text {, values of chemical shifts }(\delta, \text { ppm }) \text { and spin coupling constants } \\
(J, \mathrm{~Hz})\end{array}$} \\
\hline & 1 & 2 & 3 & 4 & 5 & 6 & 7 & 8 \\
\hline $2^{2}$ & $\begin{array}{c}36.7(\mathrm{ddt}) \\
J_{\mathrm{F} \mathrm{F}}=65 \\
J_{\mathrm{F} \mathrm{F}^{4}}=18 \\
J_{\mathrm{F}_{\mathrm{F}} 3} \approx \mathrm{J}_{\mathrm{F} 1 \mathrm{~F} 5} \\
\approx 2\end{array}$ & $\begin{array}{c}9.2(\mathrm{brs} \\
1 \mathrm{H}, \mathrm{NH}) \\
2.2(3 \mathrm{H}, \\
\left.\mathrm{CH}_{3}\right)\end{array}$ & $\begin{array}{l}22.1 \\
(\mathrm{~m})\end{array}$ & $\begin{array}{c}14.7(\mathrm{dt}) \\
J_{\mathrm{F} 445}=63 \\
J_{\mathrm{F}^{4} \mathrm{~F}} \approx \mathrm{J}_{\mathrm{F} 4 \mathrm{~F}} 1 \\
\approx 18\end{array}$ & $\begin{array}{c}45.5 \\
(\mathrm{ddd}) \\
J_{\mathrm{F} 5 \mathrm{~F} 4}= \\
63 \\
J_{\mathrm{F} 5 \mathrm{~F} 8}=18 \\
J_{\mathrm{F} 5} \mathrm{H}_{6} \approx \\
12\end{array}$ & $\begin{array}{c}7.6(\mathrm{td}, \\
1 \mathrm{H}) \\
J_{\mathrm{H} 6 \mathrm{~F} 5} \approx \\
J_{\mathrm{H}^{6} \mathrm{~F}} \approx 12 \\
J_{\mathrm{H}^{6} \mathrm{~F} 8}=6\end{array}$ & $27.0(\mathrm{~m})$ & $\begin{array}{c}13.2(\mathrm{dtt}) \\
J_{\mathrm{F} 8 \mathrm{~F} 1}=65 \\
J_{\mathrm{F} 8 \mathrm{~F} 7} \approx \\
J_{\mathrm{F}^{8} 5} \approx 18 \\
J_{\mathrm{F}^{8} \mathrm{H}^{6}} \approx \\
J_{\mathrm{F} 8 \mathrm{~F}^{4}} \approx 4\end{array}$ \\
\hline 3 & $\begin{array}{c}18.5(\mathrm{dd}) \\
J_{\mathrm{F} 1 \mathrm{~F} 8}=63 \\
J_{\mathrm{F} 1 \mathrm{~F} 4}=18\end{array}$ & $\begin{array}{c}7.6(\mathrm{brs} \\
1 \mathrm{H}, \mathrm{NH}) \\
2.3(3 \mathrm{H}, \\
\left.\mathrm{CH}_{3}\right)\end{array}$ & $\begin{array}{c}8.4 \\
(\mathrm{dd}, 1 \mathrm{H}) \\
J_{\mathrm{H}^{3} \mathrm{~F} 4} \approx \\
14 \\
J_{\mathrm{H}^{3} \mathrm{~F} 1}= \\
6\end{array}$ & $\begin{array}{c}45.0 \\
(\mathrm{ddd}) \\
J_{\mathrm{F} 4 \mathrm{~F}^{5} 5}=68 \\
J_{\mathrm{F}^{4} \mathrm{~F} 1} \approx 18 \\
J_{\mathrm{F}^{4} \mathrm{H}^{3}} \approx 14\end{array}$ & $\begin{array}{c}46.0 \\
(\mathrm{ddd}) \\
J_{\mathrm{F} 5 \mathrm{~F}^{4}}= \\
68 \\
J_{\mathrm{F} 5} \approx 18 \\
\mathrm{~J}_{\mathrm{F} 5} \mathrm{H}^{6} \approx \\
12\end{array}$ & $\begin{array}{c}7.0(\mathrm{td}, \\
1 \mathrm{H}) \\
J_{\mathrm{H} 6 \mathrm{~F} 5} \approx \\
J_{\mathrm{H}^{6} \mathrm{~F}} \approx 12 \\
J_{\mathrm{H}^{6} \mathrm{~F} 8}=6\end{array}$ & $27.4(\mathrm{~m})$ & $\begin{array}{c}10.4(\mathrm{dtd}) \\
J_{\mathrm{F} 8 \mathrm{~F} 1}=63 \\
J_{\mathrm{F} 8 \mathrm{~F} 7} \approx \\
J_{\mathrm{F} 8 \mathrm{~F} 5} \approx 18 \\
J_{\mathrm{F} 8 \mathrm{H}^{6}}=6\end{array}$ \\
\hline 4 & $\begin{array}{c}20.5 \\
(\mathrm{ddm}) \\
J_{\mathrm{F} 1 \mathrm{~F} 8}=69 \\
J_{\mathrm{F} 1_{\mathrm{F}} 4}=18\end{array}$ & $\begin{array}{c}7.5(\mathrm{br} \mathrm{s} \\
1 \mathrm{H}, \mathrm{NH}) \\
2.3(3 \mathrm{H} \\
\left.\mathrm{CH}_{3}\right)\end{array}$ & $\begin{array}{c}8.4(\mathrm{dd}, \\
1 \mathrm{H}) \\
J_{\mathrm{H}^{3} \mathrm{~F} 4} \approx \\
14 \\
J_{\mathrm{H} 3 \mathrm{~F} 1}= \\
6\end{array}$ & $\begin{array}{c}43.0 \\
(\mathrm{ddd}) \\
J_{\mathrm{F} 4 \mathrm{~F}^{5}}=61 \\
J_{\mathrm{F} 4 \mathrm{~F} 1}=18 \\
J_{\mathrm{F}^{4} \mathrm{H}^{3}} \approx 14\end{array}$ & $\begin{array}{c}12.6 \\
(\mathrm{dtd}) \\
J_{\mathrm{F} 5} \mathrm{~F}^{4}= \\
61 \\
J_{\mathrm{F} 5 \mathrm{~F} 8} \approx \\
J_{\mathrm{F}^{5} \mathrm{~F}} \approx 18 \\
J_{\mathrm{F}^{5} \mathrm{H}^{7}} \approx 6\end{array}$ & 24.8 & $\begin{array}{c}7.1(\mathrm{td}, \\
1 \mathrm{H}) \\
J_{\mathrm{H}^{7} \mathrm{~F} 8} \approx \\
J_{\mathrm{H}^{7} \mathrm{~F}} \approx 12 \\
J_{\mathrm{H}^{7} \mathrm{~F}^{5}}=6\end{array}$ & $\begin{array}{c}43.7 \text { (ddd) } \\
J_{\mathrm{F} 8 \mathrm{~F} 1}=69 \\
J_{\mathrm{F} 855}=18 \\
J_{\mathrm{F} 8 \mathrm{H}^{7}} \approx 12\end{array}$ \\
\hline $\mathbf{5}^{2,3}$ & $\begin{array}{c}8.9(\mathrm{dt} \\
1 \mathrm{H}) \\
J_{\mathrm{H}^{1} \mathrm{~F} 3}=6 \\
J_{\mathrm{H}^{1} \mathrm{~F}}= \\
J_{\mathrm{H}^{1} \mathrm{~F} 5}=1.5\end{array}$ & - & $7.8(\mathrm{~m})$ & $\begin{array}{c}16.1 \\
(\mathrm{dddt}) \\
J_{\mathrm{F} 44_{\mathrm{F}} 5}=54 \\
J_{\mathrm{F}_{\mathrm{F}} 3}=15 ; \\
J_{\mathrm{F}_{4} 8}=3 \\
J_{\mathrm{F}^{4} \mathrm{H}^{1}}= \\
J_{\mathrm{F}^{4} \mathrm{~F}^{7}}=1.5\end{array}$ & $\begin{array}{c}41.4 \\
(\mathrm{dtm}) \\
J_{\mathrm{F} 5 \mathrm{~F}^{4}}= \\
54 \\
J_{\mathrm{F} 5 \mathrm{~F}^{8}} \approx \\
J_{\mathrm{F} 5 \mathrm{H}^{6}} \approx 16\end{array}$ & - & $22.6(\mathrm{~m})$ & $\begin{array}{c}7.4(\mathrm{tdt}, \\
J_{\mathrm{F} 8 \mathrm{~F} 7} \approx J_{\mathrm{F} 8 \mathrm{~F} 5} \\
\approx 16 \\
J_{\mathrm{F}^{8}, \mathrm{H}^{6}}=6 ; \\
J_{\mathrm{F} 8 \mathrm{~F}^{4}}=3 \\
J^{4}=3\end{array}$ \\
\hline $6^{2}$ & $\begin{array}{c}9.1(\mathrm{dd}, \\
1 \mathrm{H}) \\
J_{\mathrm{H}^{1} \mathrm{~F}}= \\
7.5 \\
J_{\mathrm{H}^{1} \mathrm{H}^{4}}= \\
1.5\end{array}$ & $\begin{array}{c}9.4(\mathrm{br} \mathrm{s} \\
1 \mathrm{H}, \mathrm{NH}) \\
2.3(3 \mathrm{H} \\
\left.\mathrm{CH}_{3}\right)\end{array}$ & $\begin{array}{l}37.0 \\
(\mathrm{~m})\end{array}$ & $\begin{array}{c}7.8(\mathrm{dd}, \\
1 \mathrm{H}) \\
J_{\mathrm{H}^{4} \mathrm{~F}^{3}}= \\
11.5 \\
J_{\mathrm{H}^{4} \mathrm{H}^{1}}=1.5\end{array}$ & $39.6(\mathrm{~m})$ & $\begin{array}{c}7.4(\mathrm{td}, \\
1 \mathrm{H}) \\
J_{\mathrm{H} 6 \mathrm{~F} 5} \approx \\
J_{\mathrm{H}^{6} \mathrm{~F}} \approx 11 \\
J_{\mathrm{H} 6 \mathrm{~F} 8}=6\end{array}$ & $\begin{array}{c}23.7 \\
(\mathrm{dddd}) \\
J_{\mathrm{F}^{7} \mathrm{~F}}= \\
18 ; J_{\mathrm{F}^{7} \mathrm{H}} 6 \\
=11 \\
J_{\mathrm{F} 7 \mathrm{~F}^{5}=7}=7 \\
J^{4}=2\end{array}$ & $\begin{array}{c}9.5(\mathrm{tm}) \\
J_{\mathrm{F} 8 \mathrm{~F} 7} \approx \\
J_{\mathrm{F} 8 \mathrm{~F} 5} \approx 18\end{array}$ \\
\hline
\end{tabular}


Table 3. Continued

\begin{tabular}{|c|c|c|c|c|c|c|c|c|}
\hline \multirow[t]{2}{*}{$\begin{array}{l}\text { Comp } \\
\text { ound }\end{array}$} & \multicolumn{8}{|c|}{$\begin{array}{l}\text { Position of the substituent }{ }^{1} \text {, values of chemical shifts }(\delta, \mathrm{ppm}) \text { and spin coupling constants } \\
\qquad(J, \mathrm{~Hz})\end{array}$} \\
\hline & 1 & 2 & 3 & 4 & 5 & 6 & 7 & 8 \\
\hline 7 & $\begin{array}{c}10.7 \\
(\mathrm{ddm}) \\
J_{\mathrm{F}^{1} \mathrm{~F} 8}=57 \\
J_{\mathrm{F}^{1} \mathrm{~F}^{4}}=18\end{array}$ & $\begin{array}{c}4.1 \text { (br s, } \\
2 \mathrm{H} \\
\left.\mathrm{NH}_{2}\right)\end{array}$ & $\begin{array}{c}6.7(\mathrm{dd}, \\
1 \mathrm{H}) \\
J_{\mathrm{H}^{3} \mathrm{~F}^{4}} \approx \\
12 \\
J_{\mathrm{H}^{3} \mathrm{~F} 1}= \\
6.5\end{array}$ & $\begin{array}{c}42.3 \\
(\mathrm{ddd}) \\
J_{\mathrm{F}^{4} \mathrm{~F} 5}=68 \\
J_{\mathrm{F}^{4} \mathrm{~F} 1}=18 \\
J_{\mathrm{F}^{4} \mathrm{H}^{3}} \approx 11\end{array}$ & $\begin{array}{c}44.7 \\
(\mathrm{ddd}) \\
J_{\mathrm{F}^{5} \mathrm{~F}^{4}}= \\
68 \\
J_{\mathrm{F} 5 \mathrm{~F} 8} \approx 16 \\
J_{\mathrm{F}^{5} \mathrm{H}^{6}} \approx 13\end{array}$ & $\begin{array}{c}6.8(\mathrm{td}, \\
1 \mathrm{H}) \\
J_{\mathrm{H} 6 \mathrm{~F} 5} \approx \\
J_{\mathrm{H}^{6} \mathrm{~F}} \approx 11 \\
J_{\mathrm{H}^{6} \mathrm{~F}}=6\end{array}$ & $26.0(\mathrm{~m})$ & $\begin{array}{c}8.0(\mathrm{dtd}) \\
J_{\mathrm{F} 8 \mathrm{~F} 1}=57 \\
J_{\mathrm{F} 8 \mathrm{~F} 7} \approx \\
J_{\mathrm{F}^{8} 5} \approx 18 \\
J_{\mathrm{F} 8, \mathrm{H}^{6}}=5\end{array}$ \\
\hline 8 & $\begin{array}{c}15.0 \\
(\mathrm{dddt}) \\
J_{\mathrm{F} 1 \mathrm{~F} 8}=57 \\
J_{\mathrm{F} 1 \mathrm{~F} 4}=16 \\
J_{\mathrm{F} 1 \mathrm{~F} 3}= \\
11 ; J^{4}=2\end{array}$ & $\begin{array}{c}4.3 \text { (br s, } \\
2 \mathrm{H} \\
\left.\mathrm{NH}_{2}\right)\end{array}$ & $7.3(\mathrm{~m})$ & $\begin{array}{c}13.0 \\
(\mathrm{dddd}) \\
J_{\mathrm{F}^{4} \mathrm{~F} 5}=63 \\
J_{\mathrm{F}^{4} \mathrm{~F}^{3}} \approx 18 \\
J_{\mathrm{F}^{4} \mathrm{~F}}=16 ; \\
J_{\mathrm{F} 4 \mathrm{~F} 8}=4\end{array}$ & $\begin{array}{c}43.5 \\
(\mathrm{ddm}) \\
J_{\mathrm{F}^{5} \mathrm{~F}^{4}}= \\
63 \\
J_{\mathrm{F} 5}= \\
18\end{array}$ & $\begin{array}{c}6.9(\mathrm{td}, \\
1 \mathrm{H}) \\
J_{\mathrm{H}^{6} \mathrm{~F} 5} \approx \\
J_{\mathrm{H}^{6} \mathrm{~F} 7} \approx 11 \\
J_{\mathrm{H} 6 \mathrm{~F} 8}=6\end{array}$ & $25.1(\mathrm{~m})$ & $\begin{array}{c}8.5(\mathrm{dtt}) \\
J_{\mathrm{F} 8 \mathrm{~F} 1}=57 \\
J_{\mathrm{F} 8 \mathrm{~F} 7} \approx \\
J_{\mathrm{F} \mathrm{F}^{5}} \approx 18 \\
J_{\mathrm{F}^{8} \mathrm{H}^{6}} \approx \\
J_{\mathrm{F} 8 \mathrm{~F}^{4}} \approx 4\end{array}$ \\
\hline 9 & $\begin{array}{c}7.2(\mathrm{dd} \\
1 \mathrm{H}) \\
J_{\mathrm{H}^{1} \mathrm{~F}}= \\
8.5 \\
J_{\mathrm{H}^{1} \mathrm{H}^{4}}=1\end{array}$ & $\begin{array}{c}4.3 \text { (br s, } \\
2 \mathrm{H} \\
\left.\mathrm{NH}_{2}\right)\end{array}$ & $\begin{array}{l}30.2 \\
(\mathrm{~m})\end{array}$ & $\begin{array}{c}7.6(\mathrm{dd}, \\
1 \mathrm{H}) \\
J_{\mathrm{H}^{4} \mathrm{~F}^{3}}= \\
11.5 \\
J_{\mathrm{H}^{4} \mathrm{H}^{1}}=1\end{array}$ & $37.4(\mathrm{~m})$ & $\begin{array}{c}6.8(\mathrm{td}, \\
1 \mathrm{H}) \\
J_{\mathrm{H}^{6} \mathrm{~F} 5} \approx \\
J_{\mathrm{H}^{6} \mathrm{~F} 7} \approx 10 \\
J_{\mathrm{H}^{6} \mathrm{~F} 8}=6\end{array}$ & $\begin{array}{c}21.6 \\
\text { (dddd) } \\
J_{\mathrm{F} 7 \mathrm{~F} 8}= \\
18 ; J_{\mathrm{F} 7 \mathrm{H}^{6}} \\
=10 \\
J_{\mathrm{F} 7 \mathrm{~F} 5}=6 ; \\
J^{4}=2\end{array}$ & $\begin{array}{c}6.2(\mathrm{tm}) \\
J_{\mathrm{F} 8 \mathrm{~F} 7} \approx \\
J_{\mathrm{F} 8 \mathrm{~F} 5} \approx 18\end{array}$ \\
\hline
\end{tabular}

${ }^{1}$ The substituent - a fluorine atom if other is not specified; ${ }^{2}$ The solvent is $\left(\mathrm{CD}_{3}\right)_{2} \mathrm{CO} ;{ }^{3}$ The exact assignment of some signals in ${ }^{1} \mathrm{H}$ NMR spectra is difficult because of overlapping of signals of compounds $3,4,5,6 ;{ }^{4}$ The exact assignment of inter-ring spin coupling constants is difficult with a zinc cation. To check up, whether this corresponds to the observable fluorine removal from position 6 of amide $\mathbf{1}$, we calculated the geometrical structure and SOMO of its RA $\mathbf{1}^{-}$by the ROB3LYP 6-31+G* method (Figure 1). One can see that the single occupied MO (SOMO) in this RA is dispersed over a naphthalene nucleus, and the electron density is somewhat larger in the tetrafluorinated ring, thus promoting a fluoride ion elimination from this ring. Nevertheless, no possibility to unequivocally infer, in which position the RA decay should occur, is provided by these data.

In ${ }^{19} \mathrm{~F}$ NMR spectra of product mixtures (Table 3, entries 6-8) amide $\mathbf{5}$ is identified by five fluorine signals, two of which (at 41.4 and $16.1 \mathrm{ppm}$ ) display doublet splittings with $J(\mathrm{FF})_{\text {peri }}=$ $54 \mathrm{~Hz}$ that allows to refer them to $\mathrm{F}^{4}$ and $\mathrm{F}^{5}$. Besides, the signals at 41.4 and 20.9 ppm belong to $\mathrm{F}^{5}$ and $\mathrm{F}^{7}$, respectively, as being located and structured similarly to their analogs in the spectrum of 
2, thus indicating that no changes occur in going from $\mathbf{2}$ to $\mathbf{5}$ in a ring not containing the acetylamino group.

The concomitant up-field shift of $\mathrm{F}^{8}$ by $5.8 \mathrm{ppm}$ results, apparently, from the $\mathrm{F}^{1}$ replacement by hydrogen in the adjacent $\alpha$-position (compare the NMR ${ }^{19} \mathrm{~F}$ characteristics of octafluoro- and $\alpha-\mathrm{H}$ - heptafluoronaphthalene. ${ }^{18}$ This agrees with the fact that $\mathrm{F}^{3}$ undergoes considerable up-field shift $(14.3 \mathrm{ppm})$ which cannot be explained only by change of a substituent electronic effect resulting from the $\mathrm{F}^{1}$ replacement by hydrogen (see ${ }^{19}$ ), but, obviously, is caused by the concomitant increased coplanarity of the acetamido group and, as a consequence, of the nitrogen conjugation with the naphthalene framework. In a ${ }^{19} \mathrm{~F}$ NMR spectrum of 6 , the $\delta$ values of $\mathrm{F}^{5}, \mathrm{~F}^{7}$ and $\mathrm{F}^{8}$ are almost the same and the $\mathrm{F}^{3}$ signal is low-field shifted by 26.3 ppm compared with 5 that testifies an occupation of ortho-position by hydrogen rather than by fluorine.

\section{Discussion of the reaction mechanism}

Hydrodefluorination of amide (1). Rationalization of the revealed orientation of hydrodefluorination of amides $\mathbf{1}$ and $\mathbf{2}$ by zinc in aqueous ammonia is based on the previously proved notion ${ }^{9}$ that key stages in this process are single electron reduction of a substrate and the subsequent fast fragmentation of a derived radical anion (RA) with an elimination of fluoride anion and formation of a polyfluoroaryl radical. The latter is reduced to a polyfluoroaryl anion, the protonation of which completes the formation of a hydrodefluorination product. With reference to amide $\mathbf{1}$, this is depicted by Scheme 3 .

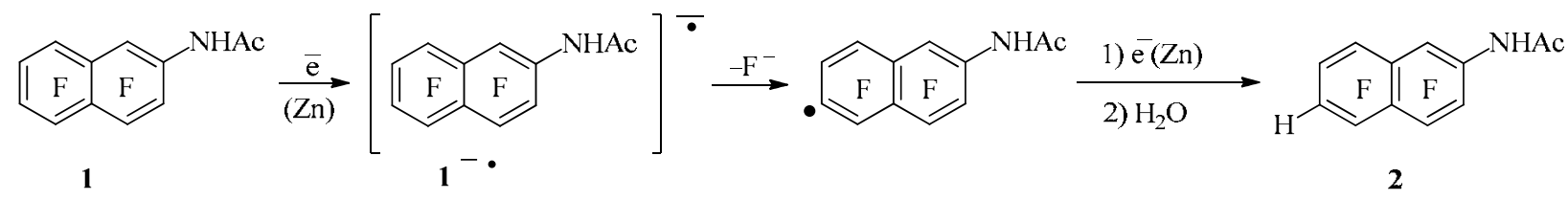

Scheme 3. Mechanism of hydrodefluorination of amide $\mathbf{1}$.

According to this scheme, it has been shown for the hydrodefluorination of amide $\mathbf{1 0},{ }^{9}$ that removal of fluorine para to the acetamido group occurring in the initial phase of the process, that is without a participation of zinc cations, is consistent with the quantum-chemically calculated structure of RA $\mathbf{1 0}^{-}$including the significant out-of-plane deviation of the para-C-F bond. Since the fragmentation of a planar RA is symmetry forbidden and demands the breaking $\mathrm{C}-\mathrm{F}$ bond to out-of-plane deviate in the transition state (TS), ${ }^{20}$ the occurrence of such deviation in the RA ground state is the important prerequisite for its realization.

However, as soon as zinc cations accumulate enough in the reaction course or a zinc salt is added $a b$ initio, the ortho-fluorine removal becomes prevailing. This specific effect was explained by formation of the complex of amide $\mathbf{1 0}$ with a zinc cation, the latter being coordinated with the oxygen atom of the acetyl group. As a stronger electron acceptor, this complex was supposed to be reduced faster than amide $\mathbf{1 0}$ itself, and the reduction product, as a 
result of an additional innercomplex coordination of a zinc cation with the ortho-fluorine, eliminates $\mathrm{ZnF}^{+}$to yield the corresponding polyfluorinated ortho-acetamidoaryl radical. ${ }^{9}$

Compound $\mathbf{1}$ is defluorinated by zinc in aqueous ammonia not via the position ortho to the acetamido group throughout the entire reaction or even upon the initial addition of a zinc salt (Table 1). This forces one to think that the free substrate is reduced in this case rather than its.
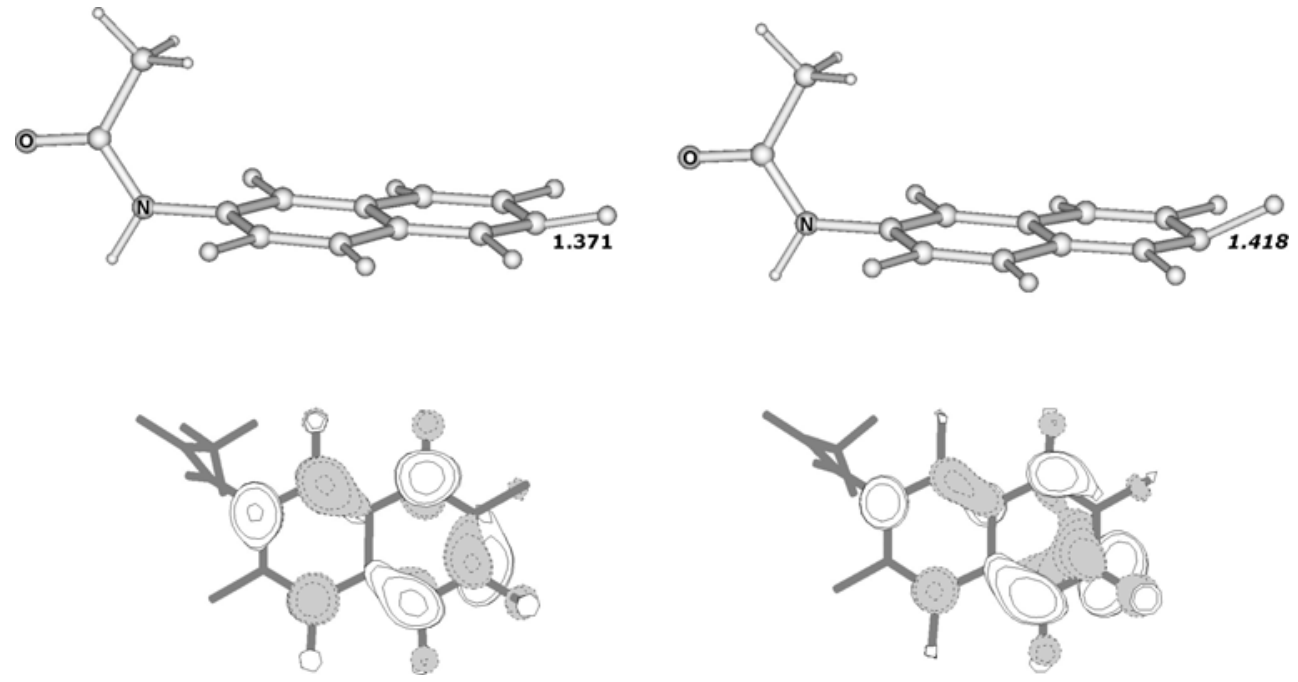

Figure 1. The B3LYP calculated geometrical structure and SOMO of RA $\mathbf{1}^{-\bullet}$ in a gas phase (left) and in a water solution (right). Shown is length $(\AA)$ of the breaking $C-F^{6}$ bond.

However the calculation of RA $\mathbf{1}^{-\bullet}$ implemented within the CPCM model with accounting the solvent (water) influence led to single electron location almost completely in the tetrafluorinated benzene moiety and mainly on the $\mathrm{C}-\mathrm{F}^{6}$ bond (Figure 1). This manifests itself in the appreciable $\sigma^{*}$ C-F-MO contribution in the SOMO, as well as in lengthening the $\mathrm{C}-\mathrm{F}^{6}$ bond by $0.05 \AA$ compared with the gas-phase RA and in its out-of-plane deviation, both being preconditions for a fragmentation of the solvated RA $\mathbf{1}^{-}$at position 6 . This is actually observed in the hydrodefluorination of $\mathbf{1}$ to be one more demonstration of the tendency to a concurrence of orientations in the polyfluoroarene RAs fragmentation, on the one hand, and in the fluorine nucleophilic substitution in their neutral precursors, on the other. In turn, this concurrence testifies the certain similarity of transition states (TS) in these reactions. This similarity presumes an opportunity to model the RA fragmentation TSs by structures of the RA $\sigma$-complexes formally formed by a single electron as a nucleophile (for detailed discussion see ${ }^{9}$ ). Like the fluorine nucleophilic substitution in polyfluoroarenes, in particular in polyfluoronahthalenes ${ }^{5}$, preferable is the fragmentation of RA $\mathbf{1}^{-\bullet}$ at one of $\beta$-positions of the tetrafluorinated ring. According to these notions, its realization at position 6 rather than at position 7 may be explained by comparison of two RA $\sigma$-complexes 11 and 12, which differ by permutation of the fluorine and acetamido substituents in the $\beta$-positions of other ring and by the interaction of each of them with the negative charge located on a respective ipso carbon atom. In structure 11, which models the TS 
of the experimentally observed hydrodefluorination at position 6 , the negative charge does not experience an essential destabilizing electron-releasing effect of the nitrogen atom owing to the latter's conjugation with the carbonyl group and out-of-plane rotation of the acetamido group. As a result, this group exerts, obviously, only a weak electron-withdrawing and, accordingly, stabilizing effect with respect to the ring. Unlike this, in structure 12, corresponding to the fluorine removal from position 7 , a destabilizing repulsion occurs between the negative charge and the fluorine electron pair (cf. ${ }^{21}$ ). Legitimacy of such qualitative evaluation was supported by the calculation under the program "Priroda" in the PBE/3z approximation ${ }^{22}$ of the model $\sigma$-complexes corresponding to a fluoride anion addition to the 6- and 7-positions of 1 which has shown that the first one is $\sim 2 \mathrm{kcal} / \mathrm{mol}$ more stable than the second.

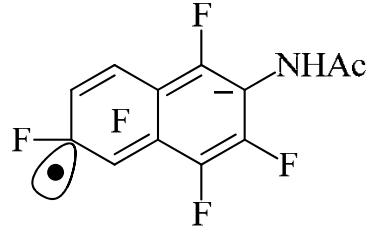

11

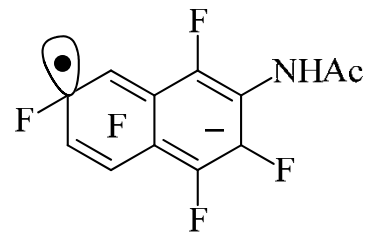

12

Naturally, a question arises as to why in this case, unlike amide 10, the free amide is reduced rather than its zinc cation complex. This fact stands with the found out earlier hydrodefluorinations of para-acetamidotetrafluorobenzonitrile at the position ortho to a cyano group and 4acetamidononafluorobiphenyl at position 4, ${ }^{15,16}$ These compounds and amide $\mathbf{1}$ differ from amide 10 by the presence, instead of para-fluorine, of the fragment, exerting an electronwithdrawing resonance effect to diminish the nitrogen conjugation with the carbonyl group and, respectively, the oxygen basicity. Besides, it is not excluded that amide $\mathbf{1}$ is less soluble in aqueous ammonia than amide 10. Both these factors should diminish the equilibrium content of the zinc cation complex of $\mathbf{1}$ in relation to the free $\mathbf{1}$ that benefits the latter's reduction.

This concentration factor can be additionally strengthened by an expected larger electron affinity of naphthamide $\mathbf{1}$ in comparison with benzamide 10, that proved to be true by the calculated (B3LYP/6-31+G*) values of gase-phase adiabatic electron affinities (AEA) of $1.06 \mathrm{eV}$ for $\mathbf{1}$ and $0.74 \mathrm{eV}$ for $\mathbf{1 0}$. The account of a solvation by water gave 2.50 and $2.32 \mathrm{eV}$ for $\mathbf{1}$ and $\mathbf{1 0}$, accordingly, thus reflecting, first, a significance of solvation of their RAs by a polar solvent and, secondly, the tendency to diminution under influence of this factor of the difference in AEA values of these amides. Keeping in mind that calculation performed describes only a nonspecific solvation, a specific one is not excluded to make the solvation contribution is even greater.

In view of a possibility that hydrodefluorinations of amides $\mathbf{1}$ and $\mathbf{1 0}$ proceed via different courses, a question arises as to whether this is due to not only the above reasons, but also the different electronic structures of single electron reduction products of the zinc complexes of 1 and 10 - radical cations (RCs) $\mathbf{1}-\mathbf{Z n}^{+\bullet}$ and $\mathbf{1 0}-\mathbf{Z n}^{+\bullet}$, respectively, we executed the corresponding "Priroda" ${ }^{22}$ calculation. Besides, as in this case the solvation influence is rather complicated to 
account, in order to evaluate the significance of this factor the radical reduction products of the protonated amides $\mathbf{1}$ and $\mathbf{1 0}\left(\mathbf{1}-\mathbf{H}^{\bullet}\right.$ and $\mathbf{1 0}-\mathbf{H}^{\bullet}$, respectively) were calculated as simplified models. The geometry optimization of their structures revealed the protonation to occur on the acetyl oxygen atom and the odd electron to be located on the acetyl carbon atom (for 10 see Figure 2). In both cases, a coordination occurs between the added proton and ortho-fluorine. For $\mathbf{1}-\mathbf{H}$ this intramolecular hydrogen bonding is minimally $(\sim 1 \mathrm{kcal} / \mathrm{mol})$ preferable for the fluorine atom occupying the $\alpha$-position of a naphthalene skeleton compared with the $\beta$-fluorine. Moreover, the calculation has shown that, already in a gas phase, the energetically favourable elimination of HF from $1-\mathbf{H}^{\bullet}$ and $\mathbf{1 0}-\mathbf{H}^{\bullet}$ occurs to form the respective ortho-acetamidoaryl radicals. In the case of $\mathbf{1 0}-\mathbf{H}^{\bullet}$ the energy barrier of this transformation was evaluated as $5.6 \mathrm{kcal} / \mathrm{mol}$ by the $\mathrm{PBE} / 3 \mathrm{z}$ calculation and $12.1 \mathrm{kcal} / \mathrm{mol}$ by the $\mathrm{B} 3 \mathrm{LYP} / 6-31+\mathrm{G}^{*}$ one. The account of solvation at the CPCM/B3LYP level did not lead to the essential redistribution of a single electron density, but reduced the reaction barrier to $7 \mathrm{kcal} / \mathrm{mol}$. At the same time, the $\mathrm{PBE} / 3 \mathrm{z}$ calculation predicted the expansion of aromatic system in going from $\mathbf{1 0}-\mathbf{H}^{\bullet}$ to $\mathbf{1}-\mathbf{H}^{\bullet}$ to noticeably increase the reaction barrier: up to 7.9 and $9.5 \mathrm{kcal} / \mathrm{mol}$ for the near-by to the $\mathrm{NHCOCH}_{3}$ group $\alpha$ - and $\beta$-positions, respectively. This result is compatible with the $\mathrm{CV}$ measurement results (vide infra).
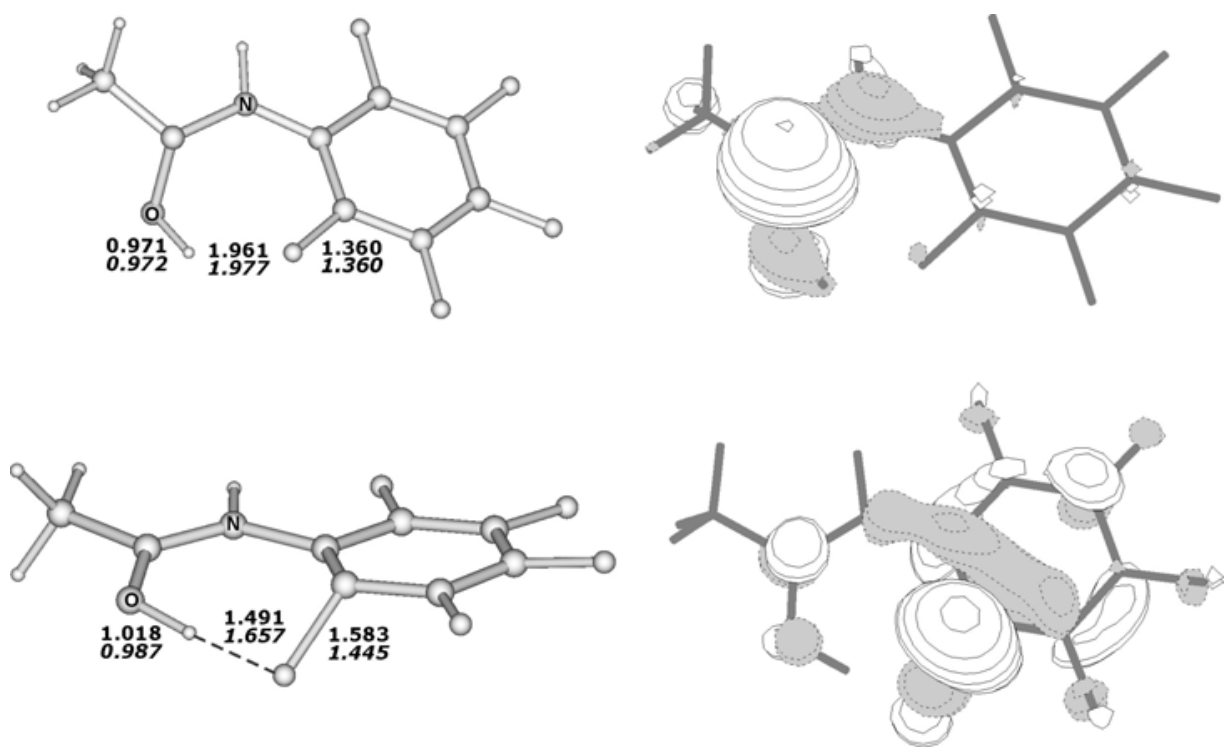

Figure 2. The calculated geometry structures and SOMOs of $\mathbf{1 0}-\mathbf{H}^{\bullet}$ (top) and its fragmentation TS (bottom). The bond length values are given in $\AA$ as typed Roman for a gas phase (B3LYP) and italics for a water solution (PCM).

Substantially, the SOMOs of RCs $\mathbf{1}-\mathbf{Z n}^{+}$and $\mathbf{1 0}-\mathbf{Z n}^{+}$, calculated by the PBE method, completely located on a zinc atom, and, by analogy to the previous case, hardly one could expect a principle change of this situation in going to an aqueous solution. However, unlike the intramolecular hydrogen bonding in $\mathbf{1}-\mathbf{H}^{\bullet}$ and $\mathbf{1 0}-\mathbf{H}^{\bullet}$, the calculated ground states of $\mathbf{1}-\mathbf{Z n}^{+\bullet}$ and $\mathbf{1 0}-\mathbf{Z n}^{+\bullet}$ exist in 
conformations, characterized by a significant out-of-plane rotation of the $\mathrm{NHCOZn}^{+\bullet}$ group relative to a neutral polyfluoroaromatic skeleton, involving no coordination $\mathrm{Zn} \cdot$ ortho-F.

Thus, it follows from these results that both in radicals $\mathbf{1}-\mathbf{H}^{\bullet}$ and $\mathbf{1 0}-\mathbf{H}^{\bullet}$ and in RCs $\mathbf{1}-\mathbf{Z n}^{+\bullet}$ and $10-\mathbf{Z n}^{+\bullet}$ the framework electronic state corresponds to that of a neutral polyfluoroarene with the lack of factors impelling a fluoride anion to leave. This allows one to assume that the detailed fragmentation mechanism of all these species consists in the intramolecular single electron transfer on the aromatic moiety. As a result, it gets the character of a polyfluoroarene RA with switching on the electronic and structural factors providing a propensity to the easy fragmentation via a C-F-bond cleavage (for detailed discussion see ${ }^{20}$ ). In the $\mathbf{1}-\mathbf{H}^{\bullet}$ and $\mathbf{1 0}-\mathbf{H}^{\bullet}$ ground states for the only but weak precondition to this the above intramolecular hydrogen bonding could probably be considered, as occurring due to a high mutual affinity of hydrogen and fluorine atoms and being a rudiment of a $\mathrm{H}-\mathrm{F}$ molecule to be eliminated in the course of fragmentation.

Unlike this, the calculated ground state structures of $\mathbf{1}-\mathbf{Z n}^{+\bullet}$ and $\mathbf{1 0}-\mathbf{Z n}^{+\bullet}$ display no features favorable for the fragmentation. In this aspect, the calculated structure of $\mathrm{RC} \mathbf{1 0}-\mathbf{Z n}^{+\bullet}$ which can be pictured by structure 13 substantially differs from the earlier ${ }^{9}$ suggested structure 14 in which an odd electron is located in the $\mathrm{N}$-(polyfluoroaryl)acetamide ligand and the $\mathrm{Zn}$ - ortho-F $^{-}$ coordination occurs, the combination of these peculiarities being favorable for a selective cleavage of ortho-C-F-bond and an elimination of the $\mathrm{ZnF}^{+}$cation.

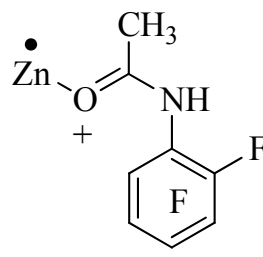

13

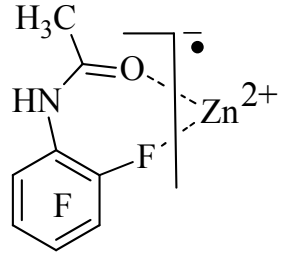

14

However, the prerequisites for the fragmentation may be believed to arise and amplify in the course of the ground state transformation to the TS, as a result of conformational tuning of the $\mathbf{1}-\mathbf{Z n}^{+\bullet}$ (as well as $\mathbf{1 0}-\mathbf{Z n}^{+\bullet}$ ) spatial structure with approaching of the coordinated zinc cation to the ortho-C-F-bond and the odd electron transfer on the polyfluoroarene moiety. This is accompanied by developing and strengthening the ortho-F $\cdots \mathrm{Zn}$ coordination and completes with an elimination of the $\mathrm{ZnF}^{+}$cation. Keeping in mind this specifications, the structures like 14 should be obviously referred to the fragmentation TSs rather than to the ground states of RC 1$\mathbf{Z n}^{+\bullet}$ and $\mathbf{1 0}-\mathbf{Z n}^{+\bullet}$.

Hydrodefluorination of amide (2). As evident from the results of the RA $\mathbf{2}^{-}$calculation, performed like that for $\mathbf{1}^{-}$, there are no basic differences in electronic structures of these RAs in a gas phase (Figure 3). 

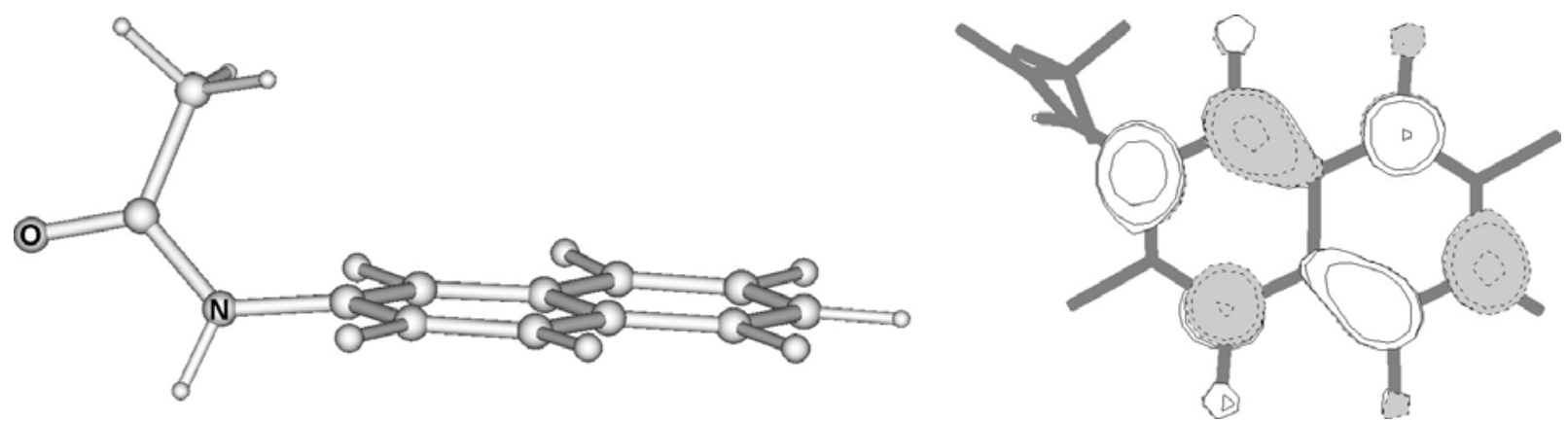

Figure 3. The geometrical structure and SOMO of RA $\mathbf{2}^{-}$according to the ROB3LYP CPCM calculations for an aqueous solution; those for a gas phase are identical.

However, unlike $\mathbf{1}^{-}$, in the case of $\mathbf{2}^{-\bullet}$ solvation by water did not appreciable change the SOMO in comparison with a gas phase, and there is no a SOMO density in position 3 , from which the fluoride removal mainly occurs. We believe that from this result the essential conclusions can be inferred, as follows. First, the redistribution of electron density in going from a gas phase to an aqueous solution predicted computationally for $\mathbf{1}^{-\bullet}$ is a cumulative consequence of the solvation and the presence in one of rings of four fluorine atoms standing alongside each other. The lack of $\mathrm{F}^{6}$, obviously, considerably weakens an electron-accepting capacity of this ring, which is not offset by solvation enough for the full odd electron location and the fluoride anion elimination from this ring. Secondly, for this reason a selective removal of fluoride anion from positions ortho to the acetamido group, mainly from position 3 (Table 1), is not determined by the structure of RA $\mathbf{2}^{-}$. Even in a polar solvent, the latter remains planar so that the fluoride anion elimination is symmetry forbidden (there is no efficient mixing of $\pi$ - and $\sigma^{\star}$-MO).

The above results compels to think that hydrodefluorination of amide $\mathbf{2}$ is oriented by the effect of zinc cations found out earlier ${ }^{8,9}$ and considered above for amide 10. Besides the basic distinction in the calculated electronic structures of $\mathbf{1}^{-}$and $\mathbf{2}^{-}$, two more factors may promote such a change of the route of this transformation in going from 1 to 2 . First, decreasing the electron-accepting capacity of the ring wherefrom one fluorine atom is removed should increase the basicity of acetyl oxygen and, accordingly, an equilibrium concentration of complex $\mathbf{2}-\mathbf{Z n}^{\mathbf{2 +}}$ relative to the free amide 2. Secondly, for the same reason one should expect a decreased substrate electron affinity that proves to be true by comparison the above AEA for $\mathbf{1}$ and the analogously calculated values of 0.98 and $2.41 \mathrm{eV}$ for 2 in a gas phase and in water, respectively. Comparing these values with those for $\mathbf{1 0}$ (vide supra), a disparity is revealed that, as shown above, amide $\mathbf{2}$ unlike $\mathbf{1 0}$ is not reduced at switching-off the zinc cation effect by a thiocyanate anion additive. In our opinion, considering actual irreversibility of the reduction caused by the subsequent fast decay of initially formed RAs (cf. ref. 23), it specifies a likelihood that the correlation of defluorination rates of amides $\mathbf{1 , 2}$ and $\mathbf{1 0}$ is caused not only by their AEA values, but also by relative propensity of their RAs to decay. The latter, obviously, is appreciably caused by the fact that $\mathbf{1}$ and 10, unlike $\mathbf{2}$, have four and five near-by located fluorine atoms, accordingly. Together with a solvation, in the case of $\mathbf{1}^{\bullet}$ this structural feature promotes a 
negative charge concentration in the tetrafluorinated ring and an out-of-plane deviation of the $\mathrm{C}-\mathrm{F}$ bond thereby facilitating the RA fragmentation. According to the data, ${ }^{20} \mathbf{1 0}^{-}$has the same prerequisites for a rapid decay.

As well as for $\mathbf{1}-\mathbf{H}^{\mathbf{*}}$, in $\mathbf{2}-\mathbf{H}^{\mathbf{*}}$ the intramolecular hydrogen bond was calculated energetically a little more preferable with $\mathrm{F}^{1}$ (in this case the difference in favour of it in comparison with $\mathrm{F}^{3}$ is only $0.3 \mathrm{kcal} / \mathrm{mol}$ ) and, accordingly, the fragmentation energy barriers were found as 9.0 and $10.3 \mathrm{kcal} / \mathrm{mol}$ for $\mathrm{F}^{1}$ and $\mathrm{F}^{3}$, respectively. This correlation is opposite to that observed in the experiment (Table 1), the latter being believed to be due to the zinc cations effect. However, the difference in calculated activation energies for the fragmentation of $\mathbf{2}-\mathbf{H}^{\mathbf{*}}$ at positions 1 and 3 is symbolic, so that for the fragmentation of $\mathbf{2}-\mathbf{Z n}^{+\bullet}$ this correlation may turn out opposite due to, for example, the TS geometrical parameters associated with the larger zinc atomic radius compared with hydrogen.

\section{Cyclic voltammetry (CV) study}

Aspiring to shed some light on the energetics of the amides 1-3 reduction, we studied their electrochemical reduction in DMF on a platinum electrode with $\mathrm{Et}_{4} \mathrm{NClO}_{4}$ as an electrolyte. The cyclic voltammogram of $\mathbf{1}$ contained two reduction peaks with $E_{\mathrm{p}}{ }^{1 \mathrm{C}}=-1.83 \mathrm{~V}$ and $E_{\mathrm{p}}{ }^{2 \mathrm{C}}=-2.15 \mathrm{~V}$ $(v=100 \mathrm{mV} / \mathrm{s}$ ), both being diffusionally controlled. The reduction irreversibility of $\mathbf{1}$ (peak 1C) is quite understandable in view of a high readiness of polyfluoroarene RAs to undergo fragmentation. ${ }^{23}$ Particular attention is drawn by a little more negative potential value of amide 1 reduction compared with amide $\mathbf{1 0}\left(-1.6 \mathrm{~V}^{9}\right)$ despite an inherently higher electron affinity of the naphthalene core compared with the benzene one. However, the correlation of $\mathbf{1}$ and $\mathbf{1 0}$ propensities to the reductive defluorination can be controlled not so much by their relative electronic affinity, how many by a correlation of the fragmentation rates of their RAs. Hence, RA $\mathbf{1}^{-\bullet}$ is not excluded to be more stable against fragmentation, than RA $\mathbf{1 0}^{-}$. This is indirectly evidenced by the results of $\mathrm{CPCM} / \mathrm{B} 3 \mathrm{LYP}$ calculation: the $\mathrm{C}^{-\mathrm{F}^{6}}$ bond in $\mathbf{1}^{-}(1.418 \AA)$ is noticeably shorter than the $\mathrm{C}-\mathrm{F}^{4}$ bond in $\mathbf{1 0}^{-}(1.439 \AA)$.

The cyclic voltammogram of 2 contained the irreversible $1 \mathrm{C}$ peak at $E_{\mathrm{p}}=-1.90 \mathrm{~V}$ which is diffusionally controlled up to $50 \mathrm{~V} / \mathrm{sec}$. The reduction potentials of $\mathbf{1}$ and $\mathbf{2}$ are close $\left(\Delta E_{\mathrm{p}}=0.07\right.$ $\mathrm{V})$, so that $\mathbf{2}$ is also reduced to some extent in conditions of the amide $\mathbf{1}$ reduction. However, assuming heterogeneity factors for reduction of $\mathbf{1}$ and $\mathbf{2}$ to be almost identical and the rates of their RA formation to be controlled basically by the reduction potentials, the above difference in $E_{\mathrm{p}}$ values corresponds to a ratio of equilibrium constants $\sim 15$ of $\mathbf{1}^{-}$and $\mathbf{2}^{-\boldsymbol{*}}$ formation at room temperature. Together with a probable smaller decay rate of $2^{-}$compared with $\mathbf{1}^{-}$owing to the general tendency to slowing down the polyfluoroarene RA fragmentation with diminishing the fluorine substitution, ${ }^{23}$ this seems capable to cause the above distinctly discernible difference in defluorination rates of amides $\mathbf{1}$ and $\mathbf{2}$. This is compatible with the more cathodic position of peak $1 \mathrm{C}$ in the case of amide $\mathbf{3}(-2.03 \mathrm{~V})$. 


\section{Solid-state molecular structures}

Crystallographic data on new compound 6 can be found in Table 4. Figure 4 depicts the solidstate molecular structure. According to the X-ray diffraction data, molecules $\mathbf{6}$ are perfectly planar in the crystal. The standard deviation from the mean plane (except $\mathrm{CH}_{3}$ fragment) is $0.044 \AA$. In general, the bond lengths 6 are in good agreement with those. ${ }^{24}$ The crystal structure of $\mathbf{6}$ reveal $\pi$-stack with a slipped-parallel arrangement of the neighboring molecules in a head-to-tail manner. The separation between the planes of $\pi$-stacked molecules is $3.35 \AA\left(\mathrm{Cg}^{*} \ldots \mathrm{Cg} 3.596(1)\right.$ $\AA$ ). In crystal packing of $\mathbf{6}$ observed is the short intermolecular contacts between molecules from the neighboring $\pi$-stacks: H1A...O1 1.98, F5...F7 2.827(2) $\AA$.

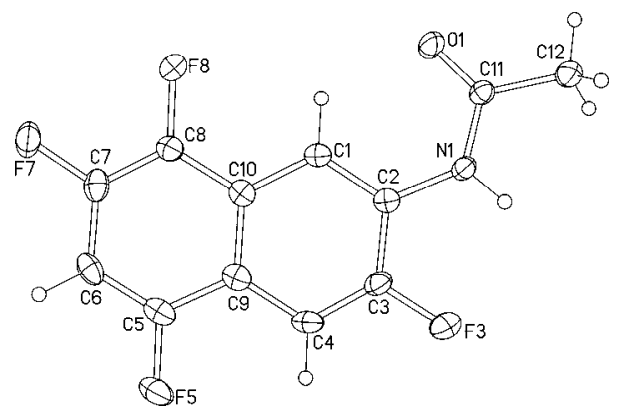

Figure 4. Spatial structure of compound 6 according to the $\mathrm{X}$-ray data.

\section{Experimental Section}

General. ${ }^{19} \mathrm{~F}$ and ${ }^{1} \mathrm{H}$ NMR spectra were recorded on a Bruker AV-300 and a Bruker AM-400 spectrometers, internal standards $-\mathrm{C}_{6} \mathrm{~F}_{6}\left(\delta_{\mathrm{F}}=0\right)$ and residual protons in deuterated solvents, respectively. HRMS data were obtained with a "DFS" spectrometer. The GC-MS analyses were performed with a Hewlett-Packard G1081A apparatus, consisting of a gas chromatograph HP 5890 series II and a mass-selective detector HP 5971 (electron impact, 70eV) by using a $30 \times 0.25 \times 0.25 \mathrm{~mm}$ column with HP-5 oil. Melting point measurements for compounds 6 and 9 were carried out in thermosystem Mettler Toledo FP900 with rate of heating $1{ }^{\circ} \mathrm{C} / \mathrm{min}$, for compound 7 - in STA system NETZSCH STA 409 PC/PG with rate of heating $10^{\circ} \mathrm{C} / \mathrm{min}$. Aqueous ammonia was "Pure" grade, zinc powder was "ZP-2". Solvents and reagents were reagent quality.

The CV measurements were performed for degassed $2 \cdot 10^{-3} \mathrm{M}$ solutions of acetamides $\mathbf{1}, \mathbf{2}, \mathbf{3}$ in DMF at $295 \mathrm{~K}$ in an argon atmosphere using CVA-1BM potentiostat equipped with a LabMaster analog-to-digital converter with multifunctional interface (Institute of Nuclear Physics, Russian Academy of Sciences, Novosibirsk). The measurements were carried out in a mode of triangular pulse potential sweep in three-electrode electrochemical cell $\left(V=5 \mathrm{~cm}^{3}\right)$ at a stationary platinum electrode $\left(S=8 \mathrm{~mm}^{2}\right)$, with $0.1 \mathrm{M} \mathrm{Et}_{4} \mathrm{NClO}_{4}$ as supporting electrolyte. The sweep rates 
Table 4. Crystallographic and refinement data for 6

\begin{tabular}{|c|c|}
\hline Compound & 6 \\
\hline Formula & $\mathrm{C}_{12} \mathrm{H}_{7} \mathrm{~F}_{4} \mathrm{NO}$ \\
\hline M & 257.19 \\
\hline$T(\mathrm{~K})$ & 150 \\
\hline$\lambda(\AA)$ & 0.71073 \\
\hline Crystal system & Monoclinic \\
\hline Space group & $P 2_{1} / \mathrm{c}$ \\
\hline$a(\AA)$ & $7.2830(5)$ \\
\hline$b(\AA)$ & $15.6962(12)$ \\
\hline$c(\AA)$ & $9.3726(7)$ \\
\hline$\beta\left(^{\circ}\right)$ & $102.374(3)$ \\
\hline$U\left(\AA^{3}\right)$ & $1046.54(13)$ \\
\hline$Z$ & 4 \\
\hline$D_{\mathrm{c}}\left(\mathrm{g} \cdot \mathrm{cm}^{-3}\right)$ & 1.632 \\
\hline$\mu\left(\mathrm{mm}^{-1}\right)$ & 0.153 \\
\hline$F(000)$ & 520 \\
\hline Crystal size (mm) & $0.6 \times 0.08 \times 0.02$ \\
\hline \multirow{2}{*}{$\theta$ range $\left(^{\circ}\right)$} & $2.6-25.5$ \\
\hline & $-6 \leq h \leq 8$ \\
\hline \multirow[t]{2}{*}{ Index range } & $-14 \leq k \leq 19$ \\
\hline & $-10 \leq l \leq 11$ \\
\hline Reflections collected & 4939 \\
\hline \multirow{2}{*}{ Independent reflections } & 1794 \\
\hline & {$\left[R_{\mathrm{int}}=0.043\right]$} \\
\hline Completeness to $\theta(\%)$ & 92.1 \\
\hline Absorption correction & Empirical \\
\hline Refinement method & $\begin{array}{l}\text { Full-matrix least- } \\
\text { squares on } F^{2}\end{array}$ \\
\hline $\begin{array}{l}\text { Data, restraints, } \\
\text { parameters }\end{array}$ & $1794,0,163$ \\
\hline Goodness-of-fit on $F^{2}$ & 1.03 \\
\hline Observed reflections & 1425 \\
\hline Final $R$ indices $[I>2 \sigma(I)]$ & $R_{1}=0.0458$ \\
\hline$R$ indices (all data) & $w R_{2}=0.1404$ \\
\hline Largest diff. peak and & 0.51 \\
\hline hole $\left(e . \AA^{-3}\right)$ & -0.30 \\
\hline
\end{tabular}

were $0.05-100 \mathrm{~V} \cdot \mathrm{s}^{-1}$, the peak potentials were quoted with reference to a saturated calomel electrode. X-ray data (Table 4) for amide 6 were obtained on a Bruker Kappa Apex II CCD 
difractometer. Absorption correction was applied using the SADABS program. The structure was solved and refined by the full-matrix least-squares method in an anisotropic approximation using the SHELXL-97 program. ${ }^{25}$ The obtained crystal structure was analyzed for short contacts between non-bonded atoms using the PLATON program. ${ }^{26}$ CCDC 785682 contains the supplementary crystallographic data for compound $\mathbf{6}$. These data can be obtained free of charge from Cambridge Crystallographic Data Center via www.ccdc.cam.ac.uk/data request/cif.

Most of the calculations were carried out using the program GAMESS $^{27}$ in a ROB3LYP with use of a standard basic set $6-31+\mathrm{G}^{*}$. The solvation influence was considered within the CPCM model with using water as a model solvent. Resource-intensive calculations of proton and zinc cation complexes of the RAs were run under the program "Priroda" in a PBE/3z approach. ${ }^{22}$ The structure and MO images were obtained by means of a program MOLDEN. ${ }^{28}$

Compound 1 was prepared according to the literature procedure. ${ }^{5}$ Aqueous ammonia (25\%) was "Pure" grade and additionally saturated with gaseous ammonia to obtain $34 \%\left(\mathrm{~d}=0.88 \mathrm{~g} / \mathrm{cm}^{3}\right)$ solution. Ammonia solution in aqueous $(95 \%)$ ethanol $\left(\mathrm{d}^{5}=0.79 \mathrm{G} / \mathrm{mL}\right)$ was prepared by gradual addition of ethanol $(300 \mathrm{~mL})$ to distilled liquid ammonia $(100 \mathrm{~mL})$ at $-70 \div-40{ }^{\circ} \mathrm{C}$ with the subsequent heating of the solution up to $\sim 5^{\circ} \mathrm{C}$. Activated zinc (powder) was prepared by a technique, ${ }^{22} \mathrm{Zn}-\mathrm{Cu}$ couple - by a technique. ${ }^{12}$ Solvents and reagents were reagent quality.

\section{General procedure for reduction of polyfluorinated naphthylacetamides by zinc in aqueous ammonia}

A mixture of a substrate, ammonia solution and, when used, a $\mathrm{ZnCl}_{2}$ additive (Table 1) was stirred for specified time at ambient temperature. Then mixture was allowed to settle, filtered, organic products were extracted by $\mathrm{CH}_{2} \mathrm{Cl}_{2}$ both from a filtrate and a precipitate. Combined extracts were dried with $\mathrm{MgSO}_{4}$ and solvent was evaporated. The residue was analyzed by NMR and, in some cases, by GC-MS. The results are presented in Table 1.

\section{General procedure for deacetylation of polyfluoronaphthylacetamides}

A mixture of a substrate, ethanol and conc. $\mathrm{HCl}$ was refluxed for $0.5-1 \mathrm{~h}$, cooled and conc. aqueous $\mathrm{NaOH}$ solution was added on stirring up to getting a weak alkaline reaction. Organic products were extracted by $\mathrm{CH}_{2} \mathrm{Cl}_{2}$. After drying the extract with $\mathrm{MgSO}_{4}$ and removal of the solvent, an amine was obtained.

$N$-(1,3,4,5,7,8-hexafluoro-2-naphthyl)acetamide (2). A product mixture $(9.30 \mathrm{~g})$ obtained from amide 1 (11.5 g) (Table 1, entry 4) was four-fold crystallized from $\mathrm{CHCl}_{3}$ to yield amide 2 (5.6 g, 50\%), mp 198-200 ${ }^{\circ} \mathrm{C}$. Anal. Calcd. (\%) for $\mathrm{C}_{12} \mathrm{H}_{5} \mathrm{~F}_{6} \mathrm{NO}$ : C, 49.15; H, 1.70; F, 38.90; N, 4.78; 293.0270. Found: C, 49.46; H, 1.87; F, 39.18; N, 4.90; $\mathrm{M}^{+} 293.0266$.

$\mathbf{N}$-(1,4,5,7,8-pentafluoro-2-naphthyl)acetamide (3). A mixture of amine $7(0.117 \mathrm{~g}, 0.5 \mathrm{mmol})$, benzene $(5 \mathrm{~mL})$, acetic anhydride $(0.204 \mathrm{~g}, 2 \mathrm{mmol})$ and conc. $\mathrm{HClO}_{4}(1 \mathrm{drop})$ was boiled for 5 min. The solvent was evaporated, the residue was washed with water $(2 \times 5 \mathrm{~mL})$, dissolved in $\mathrm{CHCl}_{3}$. The solution was dried with $\mathrm{MgSO}_{4}$, the solvent was evaporated to give amide 3 (0.135 
g, 98\%), mp $195{ }^{\circ} \mathrm{C}$. Anal. Calcd. (\%) for $\mathrm{C}_{12} \mathrm{H}_{6} \mathrm{~F}_{5} \mathrm{NO}$ : C, 52.36; H, 2.18; F, 34.55; N, 5.09. Found: C, 51.93; H, 2.33; F, 34.39; N, 5.08.

$N$-(3,5,7,8-Tetrafluoro-2-naphthyl)acetamide (6). A product mixture $(0.330 \mathrm{~g})$ obtained from amide 2 (0.412 g) (Table 1, entry 9) was five-fold crystallized from EtOH to yield amide 6 (0.114 g, 33\%), mp $223.2{ }^{\circ} \mathrm{C}$. Anal. Calcd. (\%) for $\mathrm{C}_{10} \mathrm{H}_{7} \mathrm{~F}_{4} \mathrm{NO}$ : C, 56.03; H, 2.72; F, 29.57; N, 5.45. Found: C, 56.42; H, 2.78; F, 29.58; N, 5.23.

1,4,5,7,8-Pentafluoro-2-naphthylamine (7). The mixture of products of amide 2 reduction (Table 1, entry 8) was crystallized from $\mathrm{CHCl}_{3}$, the filtrate was evaporated to give a residue $(0.098 \mathrm{~g})$ containing compounds 3 (63\%) and 7 (25\%) ( ${ }^{19} \mathrm{~F}$ NMR). Deacetylation of 3 by conc. $\mathrm{HCl}(13 \mathrm{~mL})$ with ethanol $(5 \mathrm{~mL})$ gave a product mixture $(0.084 \mathrm{~g})$ containing amine $7\left(85 \%,{ }^{19} \mathrm{~F}\right.$ NMR). The material was three-fold crystallized from hexane to isolate the individual title amine 7 (0.055 g, 47\%), mp $101.5{ }^{\circ} \mathrm{C}$. Anal. Calcd. (\%) for $\mathrm{C}_{10} \mathrm{H}_{4} \mathrm{~F}_{5} \mathrm{~N}$ : C, 51.50; H, 1.72; F, 40.77; N, 6.00. Found: C 51.52; H, 1.81; F, 40.48; N, 5.95.

$\mathbf{1 , 3}, \mathbf{4}, \mathbf{5}, \mathbf{7 , 8}$-Hexafluoro-2-naphthylamine (8). Deacetylation of $2(2.93 \mathrm{~g})$ by conc. $\mathrm{HCl}(30 \mathrm{~mL})$ with ethanol $(10 \mathrm{~mL})$ afforded amine $8(2.48 \mathrm{~g}, 98 \%), \mathrm{mp} 99-101{ }^{\circ} \mathrm{C}$. Anal. Calcd. (\%) for $\mathrm{C}_{10} \mathrm{H}_{3} \mathrm{~F}_{6} \mathrm{~N}$ : C, 47.81; H, 1.20; F, 45.42; N, 5.58. Found: C, 47.64; H, 1.26; F, 45.34; N, 5.46.

3,5,7,8-Tetrafluoro-2-naphthylamine (9). Deacetylation of $6(0.082 \mathrm{~g})$ in conc. $\mathrm{HCl}(10 \mathrm{~mL})$ with ethanol $(5 \mathrm{~mL})$ afforded amine $9(0.063 \mathrm{~g}, 97 \%), \mathrm{mp} 97.9{ }^{\circ} \mathrm{C}$. Anal. Calcd. (\%) for $\mathrm{C}_{10} \mathrm{H}_{5} \mathrm{~F}_{4} \mathrm{~N}$ : C, 55.81; H, 2.33; F, 35.35; N, 6.51. Found: C, 55.77; H, 2.38; F, 35.76; N, 6.32 .

\section{Acknowledgements}

The authors are grateful to the Russian Foundation of Basic Research for the financial support (grants 09-03-00248 and 08-03-00495).

\section{References}

* Cg - ring centroid (page 16).

1. Salvati M. E., Balog J. A., Pickering D. A.; Giese S.; Fura A.; Li W., Patel R. N., Hanson R. L., WO 2002024702, Chem. Abstr. 2002, 136, 279441.

2. Getting B.; Patrick C. R.; Tatlow J. C. J. Chem. Soc. 1962, 186.

3. Abezgauz F. I.; Sokolov S. V.; Ezerskij S. N. Zh. Vses. Khim. Obshchestva im. D.I. Mendeleeva 1965, 10(1), 113; Chem. Abstr. 1965, 62, 16152h.

4. Price D.; Suschitzky H.; Hollies J. I. J. Chem. Soc. (C) 1969, 1967.

5. Vaganova T. A.; Kusov S. Z.; Rodionov V. I.; Shundrina I. K.; Sal'nikov G. E.; Mamatyuk V. I.; Malykhin E. V. J. Fluorine Chem. 2008, 129, 4, 253.

6. Miyao Kenji, JP 294967, 2003; Chem. Abstr. 2003, 139, 330069.

7. Suh D. H.; Chung E. Y.; Rhee T. H. FR. 2769019, 1997; Chem. Abstr. 1999, 131, 45254.

8. Laev S. S.; Evtefeev V. U.; Shteingarts V. D. J. Fluorine Chem. 2001, 110, 43. 
9. Laev S. S.; Gurskaya L. Y.; Selivanova G. A.; Beregovaya I. V.; Shchegoleva L. N.; Vasilieva N. V.; Shakirov M. M.; Shteingarts V. D. Eur. J. Org. Chem. 2007, 306.

10. Panteleeva E. V.; Shteingarts V. D.; Grobe J.; Krebs B.; Triller M. U.; Rabeneck H. Z. Anorg. Allg. Chem. 2003, 629, 71.

11. Safina L. Yu.; Selivanova G. A.; Bagrjanskaja I. Yu.; Shteingarts V. D. Russ. Chem. Bull., Int. Ed. 2009, 1022.

12. Safina L. Yu.; Selivanova G. A.; Koltunov K. Yu.; Shteingarts V. D. Tetrahedron Lett. 2009, 50, 5245.

13. Selivanova G. A.; Gurskaya L. Yu.; Pokrovskii L. M.; Kollegov V. F.; Shteingarts V. D. J. Fluorine Chem. 2004, 125, 1829.

14. Saeki K.; Tomomitsu M.; Kawazoe Y.; Momota K.; Kimoto H. Chem. Pharm. Bull. 1996, 44 (12), 2254.

15. Laev S. S.; Shteingarts V. D. Tetrahedron letters 1997, 38, 21, 3765.

16. Laev S. S.; Shteingarts V. D. J. Fluorine Chem. 1999, 96, 2, 175.

17. Vlasova L. V.; Kobrina L. S.; Popkova N. V. Izv. Sib. Acad. Nauk, Ser. Khim. Nauk 1974, 4, 112; Chem. Abstr. 1974, 81, 3656b.

18. Kobrina L. S.; Shteingarts V. D.; Shchegoleva L.N. Izv. Sib. Acad. Nauk, Ser. Khim. Nauk. 1974, 1, 68. Chem. Abstr. 1974, 80, 126541.

19. (a) Boden N.; Emsley J. W.; Feeney J.; Sutcliffe L.H. Mol. Phys. 1964, 133. (b) Hogben M. G.; Graham W. A. G. J. Am. Chem. Soc. 1969, 91, 283.

20. (a) Shchegoleva, L. N.; Bilkis, I. I.; Schastnev, P. V. Chem. Phys. 1983, 82, 343. (b) Schastnev, P. V.; Shchegoleva, L. N. Molecular Distortions in Ionic and Excited States; CRC Press: Boca Raton, 1995. (c) Beregovaya I. V.; Shchegoleva L. N. Chem. Phys. Lett. 2001, 348, 501.

21. (a) Burdon J. Tetrahedron 1965, 21, 3373. (b) Chambers R. D.; Musgrave W. K. R.; Waterhouse J. S.; Williams D. L. H.; Burdon J.; Hollyhead W. B.; Tatlow J. C. J. Chem. Soc., Chem. Commun. 1974, 239. (c) Chambers R. D.; Close D.; Musgrave W. K. R.; Waterhouse J. S.; Williams D. L. H. J. Chem. Soc. Perkin Trans. 1 1977, 1774. (d) Chambers R. D.; Close D.; Williams D. L. H. J. Chem. Soc. Perkin Trans. 2 1980, 778. (e) Chambers R. D.; Seabury M. J.; Williams D. L. H.; Hughes N. J. Chem. Soc. Perkin Trans. 1 1988, 251. (f) Chambers R. D., Seabury M. J., Williams D. L. H., Hughes N. J. Chem. Soc. Perkin Trans. 1 1988, 255.

22. Laikov D. N. Chem. Phys. Lett. 1997, 281, 151.

23. Konovalov V. V.; Laev S. S.; Beregovaya I. V.; Shchegoleva L. N.; Shteingarts V. D.; Tsvetkov Y. D.; Bilkis I. J. Phys. Chem. A 2000, 104, 352.

24. Allen F. H.; Kenard O.; Watson D. G.; Bramer L.; Orpen A. G.; Taylor R. J. Chem. Soc. Perkin Trans II 1987, 12, S1.

25. Sheldrick G.M. SHELX-97 - Programs for Crystal Structure Analysis; Release 97-2, University of Goetingen, Goettingen, Germany. 
26. Spek A.L. PLATON, a multipurpose crystallographic tool (Version 10M); Utrecht University, Utrecht, The Netherlands, 2003.

27. Schmidt M. W.; Baldridge K. K.; Boatz J. A.; Elbert S. T.; Gordon M. S.; Jensen J. H.; Koseki S.; Matsunaga N.; Nguyen K. A.; Su S. J.; Windus T. L.; Dupuis M.; Montgomery J. A. J. Comput. Chem. 1993, 14, 1347.

28. G. Schaftenaar. QCPE-619. 